\title{
Apocynum venetum Extract Does Not Induce CYP3A and P-Glycoprotein in Rats
}

\author{
Michiya Kobayashi, ${ }^{a}$ Hiroshi Saitoh,,${ }^{* a}$ Shujiro Seo, ${ }^{b}$ Veronika Butterweck,,${ }^{c}$ and Sansei Nishibe ${ }^{d}$ \\ ${ }^{a}$ Department of Pharmaceutics, Faculty of Pharmaceutical Sciences, Health Sciences University of Hokkaido; Ishikari- \\ Tobetsu, Hokkaido 061-0293, Japan: ${ }^{b}$ Tokiwa Phytochemical Co.; Chiba 285-0801, Japan: ${ }^{c}$ College of Pharmacy, \\ Department of Pharmaceutics, University of Florida; FL, 32610 U.S.A.: and d Department of Pharmacognosy, Faculty of \\ Pharmaceutical Sciences, Health Sciences University of Hokkaido; Ishikari-Tobetsu, Hokkaido 061-0293, Japan. \\ Received May 12, 2004; accepted July 13, 2004; published online July 14, 2004
}

\begin{abstract}
We investigated the effect of Apocynum venetum L. extract (AV) on the activity of cytochrome P450 (CYP) 3A and P-glycoprotein (P-gp). The plasma concentration of nifedipine (NF), which is a substrate for CYP3A, did not change after oral administration with AV $(3.3 \mathrm{mg} / \mathrm{kg})$. Also, AV $(3.3$ and $33 \mathrm{mg} / \mathrm{kg})$ did not affect the intestinal absorption of NF. In the rats treated with multiple administrations $(15 \mathrm{mg} / \mathrm{kg} / \mathrm{d})$ of St. John's wort extract (SJW) for 2 weeks, the plasma concentration of NF after oral administration was significantly decreased. On the other hand, there was no significant differences in the pharmacokinetic parameters of NF between AV-treated $(3.3 \mathrm{mg} / \mathrm{kg} / \mathrm{d})$ and none-treated rats. Furthermore, the intestinal absorption of methylprednisolone, which is a substrate for P-gp, was not affected by AV treatment for 2 weeks. These results suggest that, unlike SJW, the recommended dose of $\mathrm{AV}(3.3 \mathrm{mg} / \mathrm{kg} / \mathrm{d})$ would not influence hepatic CYP3A and intestinal P-gp in rats.
\end{abstract}

Key words Apocynum venetum; St John's wort; CYP3A; P-glycoprotein; rat

Apocynum venetum L. (Luobuma in Chinese, Apocynaceae) is a wild shrub grown in Asia, and its leaves have been used as a tea in China, Japan and other Asian countries. The leaves of Apocynum venetum L. have been used in traditional Chinese medicine. It has been reported that the extract from the leaves of Apocynum venetum L. (AV) exerts various pharmacological effects including diuretic, ${ }^{1)}$ antihypertensive and antihyperlipidemic, ${ }^{2}$ and sedative effects. ${ }^{3)}$ Recently, it has been shown that AV has an antidepressant effect comparable to that of imipramine, a tricyclic antidepressant, in rats. ${ }^{4)}$

The extract of St John's wort (SJW) is a commonly used herbal medicine for antidepressant ${ }^{5)}$ in Europe and U.S.A. It is considered that hyperoside in SJW would have antidepressant effects. ${ }^{6,7)}$ On the other hand, the long-term intake of SJW is known to induce hepatic cytochrome P450 (CYP) 3A4 and the intestinal P-glycoprotein (P-gp) in humans, ${ }^{8)}$ and causes a decrease in the blood concentrations of cyclosporin, ${ }^{9)}$ indinavir ${ }^{10)}$ and digoxin. ${ }^{11)}$ However, it has not yet been revealed what compound(s) in SJW is capable of affecting metabolic enzymes and transporters. AV contains a number of phenolic compounds, ${ }^{12)}$ and hyperoside and isoquercitrin ${ }^{4)}$ are also contained in SJW. In recently, AV has come onto the market as a health food in Japan and U.S.A. Thus it is considerable that this herbal extracts would be used for an antidepressant substitute for SJW. However, the drug interaction with Apocynum has not been revealed even in animal model so far. In this study, we investigated the effect of $\mathrm{AV}$ on the drug disposition of the substrate drugs for CYP3A and/or P-gp in rats.

\section{MATERIALS AND METHODS}

Chemicals AV and SJW were supplied by Tokiwa Phytochemical Co. (Chiba, Japan). Nifedipine (NF) and methylprednisolone (MP) were obtained from Wako Pure Chem. Ind. (Osaka, Japan) and Sigma Chem. Co. (St. Louis, MO,
U.S.A.), respectively. All other reagents were of the highest grade available.

Animals Male wistar rats (Hokudo, Sapporo, Japan) were used in all studies. In this study, principles of good laboratory animal care were followed and animal experimentation was performed in compliance with Guidelines for the Care and Use of Laboratory Animals in Health Sciences University of Hokkaido, accredited by the "Principles of Laboratory Animal Care" (NIH publication \#85-25, revised 1985).

Oral Administration of Nifedipine Rats aged 8 to 9 weeks and weighing 250 to $300 \mathrm{~g}$ were fasted $15-18 \mathrm{~h}$ before the experiment with free access to water. They were then anesthetized by pentobarbitone $(40 \mathrm{mg} / \mathrm{kg})$ and administered NF $(0.4 \mathrm{mg} / \mathrm{kg}$, about $0.5 \mathrm{ml})$ dissolved in Dulbecco's phosphate buffer solution (D's PBS; $137 \mathrm{~mm} \mathrm{NaCl}, 3 \mathrm{~mm}$ $\mathrm{KCl}, 1 \mathrm{~mm} \mathrm{CaCl}, 0.5 \mathrm{~mm} \mathrm{MgCl} 2,8 \mathrm{~mm} \mathrm{Na} \mathrm{NPO}_{4}, 1.5 \mathrm{~mm}$ $\mathrm{KH}_{2} \mathrm{PO}_{4}$ and $5 \mathrm{~mm}$ D-glucose, $\mathrm{pH} 6.5$ ) with or without $\mathrm{AV}$ $(3.3 \mathrm{mg} / \mathrm{kg})$ by gastric intubation. After administration of drug, $0.5 \mathrm{ml}$ of blood was collected from the femoral vein with a heparinized syringe at $0,10,20,30,45,60,90,120$, 180 and $240 \mathrm{~min}$. The blood was immediately centrifuged at $1500 \times \boldsymbol{g}$ for $10 \mathrm{~min}$ to obtain plasma samples.

To clarify the effect of multiple dosing of AV and SJW, rats aged 6 weeks were orally administered $\mathrm{AV}(3.3 \mathrm{mg} / \mathrm{kg})$ or SJW $(15 \mathrm{mg} / \mathrm{kg})$ suspended in distilled water once a day at 10:00 am for 2 weeks. The dose of each herbal extract was decided according to the recommended dose for humans (AV: $200 \mathrm{mg} / \mathrm{d}, \mathrm{SJW}: 900 \mathrm{mg} / \mathrm{d}$ ). After continuous administration, the rats were fasted for $15-18 \mathrm{~h}$ and administered $\mathrm{NF}(0.4 \mathrm{mg} / \mathrm{kg})$ without herbal extract under anesthesia. The blood was also collected in the same manner as that stated above.

In Situ Loop Experiments Absorption experiments were carried out using an in situ loop technique as described previously ${ }^{13)}$ with a minor modification. Fasted rats aged 8 to 10 weeks were anesthetized by pentobarbital and a jejunal loop (about $20 \mathrm{~cm}$ from the pylorous, $10 \mathrm{~cm}$ in length) was 
prepared. The bile duct was tightly ligated in all experiments. After gently washing out the contents of the loop with saline, $1 \mathrm{ml}$ of D's PBS containing NF $(0.4 \mathrm{mg} / \mathrm{kg})$ with or without the herbal extract was injected into the loop. The dose of AV was 3.3 and $33 \mathrm{mg} / \mathrm{kg}$, and SJW was $15 \mathrm{mg} / \mathrm{kg}$. After $30 \mathrm{~min}$, the loop was cut off and the contents of the loop were emptied into a $10-\mathrm{ml}$ volumetric flask. The mucosal side of the loop was rinsed with a buffer to give a volume of $10 \mathrm{ml}$. Blood $(0.5 \mathrm{ml})$ was collected at 15 and $30 \mathrm{~min}$ after the experiment was started.

Everted Sac Studies The medium for all experiments was Tyrode's buffer ( $137 \mathrm{~mm} \mathrm{NaCl}, 3 \mathrm{~mm} \mathrm{KCl}, 2 \mathrm{~mm} \mathrm{CaCl}_{2}$, $2 \mathrm{mM} \mathrm{MgCl}_{2}, 12 \mathrm{~mm} \mathrm{NaHCO}, 0.4 \mathrm{~mm} \mathrm{NaH} \mathrm{PO}_{4}$ and $6 \mathrm{~mm}$ D-glucose) saturated with $\mathrm{O}_{2} / \mathrm{CO}_{2}(95: 5)$ gas mixture after preparation. The $\mathrm{pH}$ of the buffer was adjusted to 7.4 with $1 \mathrm{M} \mathrm{HCl}$ or $\mathrm{NaOH}$. Rats aged 6 weeks were orally administered AV $(3.3 \mathrm{mg} / \mathrm{kg})$ or SJW $(15 \mathrm{mg} / \mathrm{kg})$ suspension once a day for 2 weeks. The everted sac studies were performed as described by Goerg et al. ${ }^{14)}$ with minor modifications. The jejunum was excised under anesthesia and rinsed in ice-cold saline. The intestinal segments were slid onto a glass rod and the epithelial surface was exposed. After washing the mucosal surface with ice-cold saline, 5 -cm everted jejunal segments ( 4 segments per rat) were isolated. These everted segments were ligated at one end. Then, $0.2 \mathrm{ml}$ of fresh Tyrode's buffer was injected into the segment and the other end was ligated. The sac was sunk in the buffer containing $100 \mu \mathrm{M}$ MP at $37^{\circ} \mathrm{C}$. Under bubbling with a gas mixture, the permeation of the substrate from the mucosal to serosal surface across the intestine was measured by sampling the serosal buffer at 15 and $30 \mathrm{~min}$.

Analysis All samples were kept at $-30{ }^{\circ} \mathrm{C}$ until assay. The plasma NF assay was performed according to Miyazaki et $a l .{ }^{15)}$ with several modifications. A $0.1 \mathrm{ml}$ of plasma sample was mixed with $0.1 \mathrm{ml}$ of saline or NF solution (for standard curve), $0.2 \mathrm{ml}$ of butyl $p$-aminobenzoate as an internal standard $(50 \mathrm{ng} / \mathrm{ml}$ in methanol) and $0.7 \mathrm{ml}$ of acetonitrile, and then vigorously mixed for $10 \mathrm{~s}$. The mixture was centrifuged at $1500 \times \boldsymbol{g}$ for $10 \mathrm{~min}$. An aliquot of the resulting supernatant was collected into a glass tube containing $1 \mathrm{ml}$ of distilled water, and $5 \mathrm{ml}$ of chloroform/acetone mixture $(1: 1$, $\mathrm{v} / \mathrm{v})$ was added. This mixture was vigorously shaken for $10 \mathrm{~min}$ and centrifuged at $1000 \times \mathbf{g}$ for $10 \mathrm{~min}$, and the organic layer was transferred to a brown glass tube. The organic solution was dried in a rotary evaporator at $40^{\circ} \mathrm{C}$. The residue was dissolved in $0.1 \mathrm{ml}$ of the mobile phase, and $20 \mu \mathrm{l}$ of the solution was injected into the HPLC system.

The contents of the jejunal loop and everted sacs were added to the same volume of methanol and vigorously mixed for $10 \mathrm{~s}$. The mixture was let stand for $15 \mathrm{~min}$ in an ice-bath and then centrifuged at $1500 \times \boldsymbol{g}$ for $15 \mathrm{~min}$. An aliquot of the resulting supernatant was applied to HPLC.

The HPLC systems for the determination of NF and $\mathrm{MP}^{13)}$ were as follows: apparatus, Shimadzu LC-10AS (Kyoto, Japan) equipped with Shimadzu 10A UV spectrophotometric detector; column, Cosmosil 5C 18 -ARII (4.6 i.d. $\times 150 \mathrm{~mm}$, Nacalai Tesque, Kyoto, Japan) and column temperature, $55^{\circ} \mathrm{C}(\mathrm{NF})$ or $50^{\circ} \mathrm{C}(\mathrm{MP})$. The mobile phase for $\mathrm{NF}$ was $45 \%$ methanol in $10 \mathrm{~mm} \mathrm{Na}_{2} \mathrm{HPO}_{4}$ (pH 6.0 adjusted with $\mathrm{HCl}$ ) and flow rate was $1.2 \mathrm{ml} / \mathrm{min}$. For MP, the mobile phase was $40 \%$ acetonitrile in $50 \mathrm{~mm} \mathrm{KH}_{2} \mathrm{PO}_{4}$ and flow rate was
$0.8 \mathrm{ml} / \mathrm{min}$. The wave length for NF and MP was 280 and $246 \mathrm{~nm}$, respectively. The lower limits of NF and MP quantification in sample were $5 \mathrm{ng} / \mathrm{ml}$ and $20 \mathrm{pmol} / \mathrm{ml}$, respectively. The interassay coefficients of variations of NF and MP determination were lower than 5\%.

Pharmacokinetic parameters such as the maximum concentration of NF in plasma $\left(C_{\max }\right)$ and the time at $C_{\max }\left(T_{\max }\right)$ were take from the observed data. Area under the plasma concentration-time curve for 0 to $4 \mathrm{~h}\left(A U C_{0-4 \mathrm{~h}}\right)$ was calculated using the linear trapezoidal rule.

All experiments were performed on 3 to 5 rats and each data represents the mean \pm S.E.M. Statistical analysis was done using unpaired Student's $t$-test and $p<0.05$ was considered to be significant. $p<0.1$ is shown for reference.

\section{RESULTS}

Effect of Co-administration of Herbal Extract on Drug Disposition of Nifedipine To clarify the direct effects of $\mathrm{AV}$ to the absorption and metabolism of the substrate for CYP3A, we examined the oral administration of NF with AV in the first study. The plasma concentration profiles of NF after oral administration are shown in Fig. 1. The absorption of NF was rapid and $T_{\max }$ was 20 to $30 \mathrm{~min}$ with or without AV. There were no statistical differences in the pharmacokinetic parameters of NF with or without AV (data not shown).

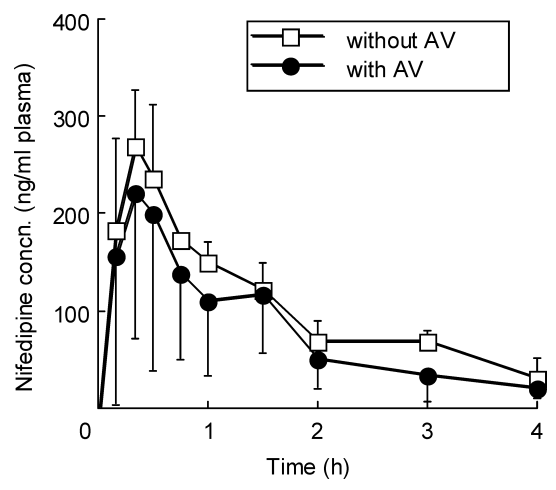

Fig. 1. Time Courses of the Plasma Concentration of Nifedipine $(0.4 \mathrm{mg} / \mathrm{kg})$ after Oral Administration with or without Apocynum venetum $\mathrm{L}$. Extract $(3.3 \mathrm{mg} / \mathrm{kg})$

Each point represents the mean with S.E.M. of 3 experiments.

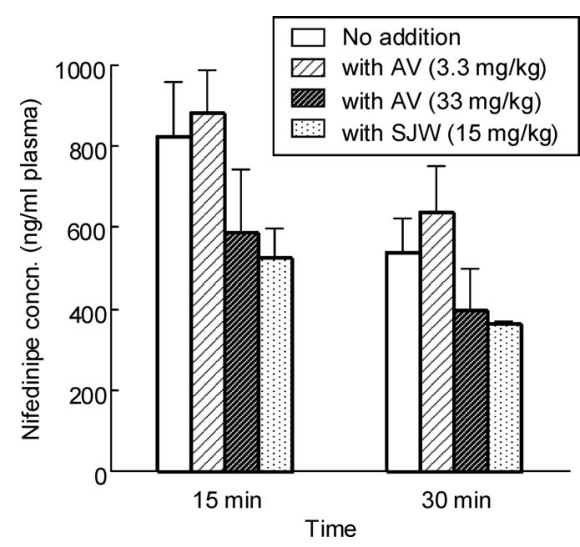

Fig. 2. Plasma Concentration of Nifedipine $(0.4 \mathrm{mg} / \mathrm{kg})$ during in Situ Loop Experiments with or without Herbal Extracts

Each column represents the mean with S.E.M. of 3 to 4 experiments. 

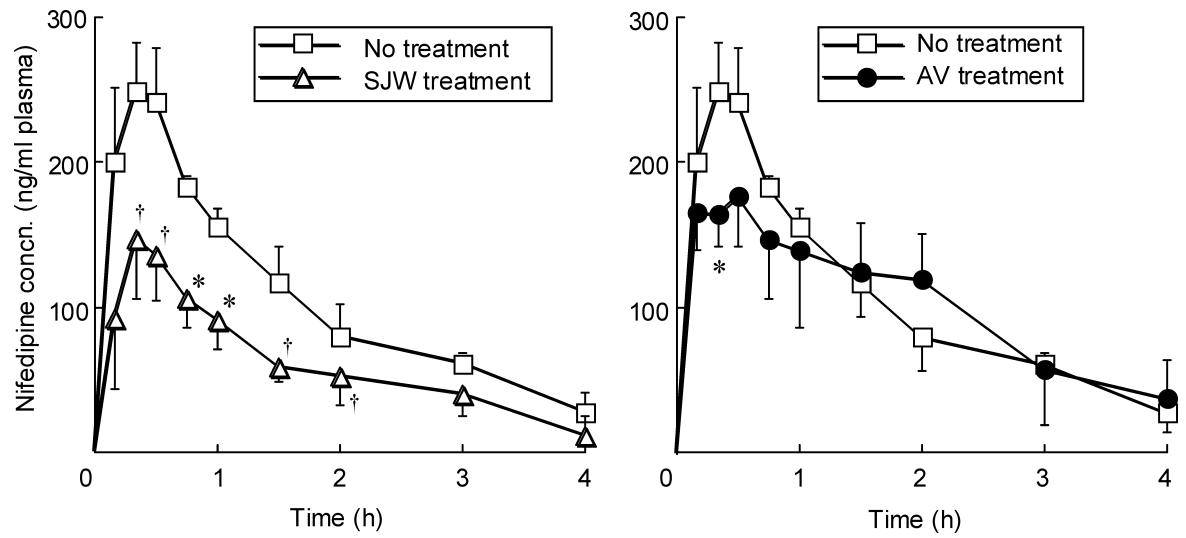

Fig. 3. Effect of a 2-Week Treatment with St John's Wort (Left) and Apocynum venetum L. Extract (Right) on the Time Courses of Plasma Concentration of Nifedipine $(0.4 \mathrm{mg} / \mathrm{kg})$ after Oral Administration

Each point represents the mean with S.E.M. of 4 to 5 experiments. $*$ Significantly different from no treatment, $p<0.05,{ }^{\dagger} p<0.1$.

Table 1. Effect of a 2-Week Treatment with Herbal Extract on the Pharmacokinetic Parameters of Nifedipine

\begin{tabular}{clcc}
\hline \hline Treatment & $C_{\max }(\mathrm{ng} / \mathrm{ml})$ & $T_{\max }(\mathrm{h})$ & $A U C_{0-4 \mathrm{~h}}(\mathrm{ng} \cdot \mathrm{h} / \mathrm{ml})$ \\
\hline No treatment & $265.3 \pm 26.1$ & $0.33 \pm 0.05$ & $426.4 \pm 54.0$ \\
AV $(3.3 \mathrm{mg} / \mathrm{kg} / \mathrm{d})$ & $216.0 \pm 31.9$ & $0.70 \pm 0.36$ & $425.5 \pm 93.3$ \\
SJW $(15 \mathrm{mg} / \mathrm{kg} / \mathrm{d})$ & $159.2 \pm 27.1^{*}$ & $0.48 \pm 0.10$ & $254.7 \pm 56.5^{\dagger}$ \\
\hline
\end{tabular}

Each data represents the mean \pm S.E.M. of 3 to 5 rats. $*$ Significantly different from no treatment, $p<0.05,{ }^{\dagger} p<0.1$.

The effect of AV and SJW on the intestinal absorption of NF from rat jejunal loops was also examined. NF almost completely disappeared from loop with or without the herbal extract after $30 \mathrm{~min}$. The percentage of disappearance was $98.3 \pm 1.7,98.1 \pm 2.3,98.9 \pm 0.8$ and $97.4 \pm 1.5$ for without herbal extract, with AV $(3.3 \mathrm{mg} / \mathrm{kg}), \mathrm{AV}(33 \mathrm{mg} / \mathrm{kg})$ and SJW $(15 \mathrm{mg} / \mathrm{kg})$, respectively. Moreover, there were no significant differences in NF plasma concentration at 15 and $30 \mathrm{~min}$ among the four experiments (Fig. 2).

Effect of 2-Weeks Treatment with Herbal Extract on Drug Disposition of Nifedipine In the rats treated with SJW for 2 weeks, the plasma levels of NF at 45 and $60 \mathrm{~min}$ after oral administration were significantly lower than those of the control rats (Fig. 3, left). Furthermore, the pharmacokinetic parameters such as $C_{\max }$ and $A U C_{0-4 \mathrm{~h}}$ were also lower than for the control group (Table 1). On the other hand, only the NF plasma level at 20 min was lower in AV-treated rats (Fig. 3, right), but there were no significant differences at the other time points and in the pharmacokinetic parameters from those in the control rats.

Effect of 2-Weeks Treatment with Herbal Extract on Absorption of Methylprednisolone To reveal the effect of $\mathrm{AV}$ on intestinal P-gp, we examined the transport of MP as a substrate for P-gp across the everted intestine from rats treated with AV or SJW for 2 weeks. As shown in Fig. 4, there were no differences in permeation at $15 \mathrm{~min}$ between the control and herbal extract-treated rats. On the other hand, the permeation of MP at $30 \mathrm{~min}$ in SJW-treated rats, unlike AV-treated rats, was significantly greater than that in the control rats.

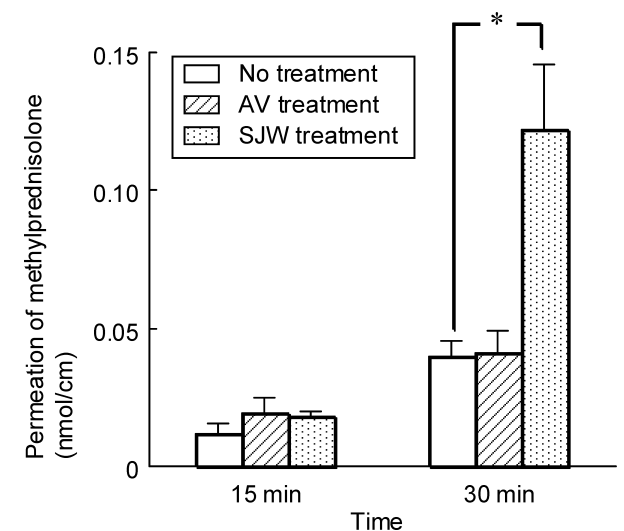

Fig. 4. Effect of a 2-Week Treatment with Apocynum venetum L. and St John's Wort Extract on the Permeation of Methylprednisolone (100 $\mu \mathrm{M})$ across the Rat Jejunal Intestine

Each column represents the mean with S.E.M. of 3 to 4 rats. * Significantly different from no treatment, $p<0.05$.

\section{DISCUSSION}

SJW is a commonly used herbal extract in Europe and U.S.A. The long-term intake of SJW causes to decrease in the efficacy of many drugs ${ }^{9-11)}$ since it induces CYP3A4 and P-gp. ${ }^{8)} \mathrm{AV}$ contains a lot of flavonoids such as hyperoside and isoquercitrin, ${ }^{4)}$ which are also contained in SJW. However, there was no information as to AV-drug interaction in not only human but in animal model. It is well known that NF is metabolized by CYP3A, and the bioavailability of NF was significantly reduced by multiple administration of rifampicin ${ }^{16)}$ and grapefruit juice ${ }^{17)}$ since they induced the CYP3A in human and rats. Moreover, we have reported that MP was a good substrate for P-gp in Caco-2 cell. ${ }^{18)}$ In the present study, therefore, we evaluated the effect of $\mathrm{AV}$ on the drug disposition of NF and MP, a substrate for CYP3A and $\mathrm{P}$-gp, respectively, in rats. A single administration of AV did not alter the plasma concentration of NF (Fig. 1). We also examined the effect of $\mathrm{AV}$ and SJW on the absorption of NF using an in situ loop technique. The absorption of NF was not changed by the recommended or a 10-fold higher dosage of AV and SJW (Fig. 2). These results suggest that a single administration of $\mathrm{AV}$ at the recommended dosage does not 
directly inhibit the activity of hepatic and intestinal CYP3A in rats.

Dürr et al. reported that intestinal P-gp and hepatic CYP3A2 were induced by the multiple administration of SJW for 2 weeks in rats. ${ }^{8)}$ Thus, we repeated the oral administration of $\mathrm{AV}$ and $\mathrm{SJW}$ for 2 weeks and then evaluated their effect on the disposition of CYP3A and P-gp substrates. After the multiple administration of SJW, the plasma concentrations of NF became significantly lower than those in the control rats (Fig. 3), which is consistent with the previous report that SJW induced hepatic CYP3A4 in humans. On the other hand, there were no differences in the plasma concentration of NF between the AV-treated and control rats. These results strongly suggest that, unlike SJW, the recommended dosage of $\mathrm{AV}$ does not induce CYP3A in rats. In our previous report, we found that the intestinal absorption of corticosteroid analogues was restricted by intestinal P-gp. ${ }^{10)}$ Thus we evaluated the effect of a long-term treatment of AV on the activity of intestinal P-gp using MP. The permeation of MP from the mucosal to serosal side of the rat intestine did not differ between the AV-treated and control rats (Fig. 4) in spite of an observation that MP transport was greatly changed in SJW-treated rats. It is still unclear what compound(s) is the cause of CYP3A and P-gp induction by SJW, however a recommended dosage of AV did not change the disposition of the substrate drugs for CYP3A and P-gp in rats. Leaves of Apocynum have been traditionally used as a tea, however, there had been no report regarding the drug interactions of this herb. The present results suggest that $\mathrm{AV}$ lacks the ability to modify the activity of CYP3A and P-gp of rats in vivo. More detailed investigations about the effects of $\mathrm{AV}$ to the other CYP and transporters in rats and human should be reported in the future.

In conclusion, our present study shows for the first time that neither a single or multiple administration of the recom- mended dose of AV $(3.3 \mathrm{mg} / \mathrm{kg} / \mathrm{d})$ changes the drug disposition via CYP3A and P-gp in rats.

\section{REFERENCES}

1) Qian Z. N., Song L. H., Gu Z. L., Chen B. Q., Zhang K. P., Li H. Z., Peng Y. K., Bull. Chin. Mater. Med., 13, 44-46 (1988).

2) Ma Y. X., Chen S. Y., Chin. J. Mod. Dev. Tradit., 9, 335-337 (1989).

3) Chen M., Liu F., Chin. J. Chin. Mat. Med., 16, 609-611 (1991).

4) Butterweck V., Nishibe S., Sasaki T., Uchida M., Biol. Pharm. Bull., 24, 848-851 (2001).

5) Linde K., Ramirez G., Mulrow C. D., Pauls A., Weidenhammer W., Melchart D., Brit. Med. J., 313, 253-258 (1996).

6) Butterweck V., Jurgenliemk G., Nahrstedt A., Winterhoff H., Planta Med., 66, 3-6 (2000).

7) Denke A., Schempp H., Weiser D., Elstner E. F., Arzneimittelforschung, 50, 415-419 (2000).

8) Dürr D., Stieger B., Kullal-Ublick G. A., Rentsch K. M., Steinert H. C., Meier P. J., Fattinger J., Clin. Pharmacol. Ther, 68, 598-604 (2000).

9) Ruschitzka F., Meier P. J., Turina M., Luscher T. F., Noll G., Lancet, 355, 548-549 (2000).

10) Piscitelli S. C., Burstein A. H., Chaitt D., Alfaro R. M., Falloon J., Lancet, 355, 547-548 (2000).

11) Johne A., Brockmoller J., Bauer S., Maurer A., Langheinrich M., Roots I., Clin. Pharmacol. Ther, 66, 338-345 (1999).

12) Fan W., Tezuka Y., Xiong Q., Hattori M., Namba T., Kadota S., Chem. Pharm. Bull., 47, 1049-1050 (1999).

13) Saitoh H., Hatakeyama M., Eguchi O., Oda M., Takada M., J. Pharm. Sci., 87, 73-75 (1998).

14) Goerg K. J., Wanitschke R., Diener M., Rummel W., Gastroenterology, 103, $781-788$ (1992).

15) Miyazaki K., Kohri N., Arita T., Shimono H., Katoh K., Nomura A., Yasuda H., J. Chromatogr., 310, 219-222 (1984).

16) Holtbecker N., Fromm M. F., Kroemer H. K., Ohnhaus E. E., Heidemann H., Drug Metab. Dispos., 24, 1121-1123 (1996).

17) Mohri K., Uesawa Y., Sagawa K., Drug Metab. Dispos., 28, 482-486 (2000).

18) Oka A., Oda M., Saitoh H., Nakayama A., Takada M., Aungst B. J., Biol. Pharm. Bull., 25, 393-396 (2002). 